\title{
Discussion on the Morphological Characteristics of Dance Performance of "Female Roles" in Gannan Tea-picking Opera
}

\author{
Xiang Wu \\ Department of Dance, School of Music, Jiangxi Normal University, Nanchang 330022, Jiangxi, China \\ Email: 170240791@qq.com
}

\begin{abstract}
Gannan tea-picking opera is a folk opera popular in the south of Jiangxi, among which "Liangdan Yichou" is the most representative way of performance. "Female roles" can be divided into "Xiao Dan" and "Cai Dan". The relationship of "Liangdan Yichou" in Gannan tea-picking opera can be roughly summarized as "the clown who plays the role of a female is responsible for matching, Zhengchou resembles the female character type in Beijing opera and "Fanchou"makes troubles. Cai Dan gives a beat of person with bad behavior. As the female character type in Beijing opera like three-inch "golden lotuses" (woman's bound feet in feudal age) encounters the exaggerated caricature like clown who plays the role of a female, the distinctive female dance performance style of Gannan tea-picking opera was formed. This paper aims to sort out and summarize the formation of the "female roles" dance performance in Gannan tea-picking opera and its unique character characteristics to have a clearer understanding of the aesthetic norms and artistic value of the dance performance of "female roles" in Gannan tea-picking opera to improve the cultural content of Gannan tea-picking opera and promote the inheritance and development of Gannan tea-picking opera as a whole.
\end{abstract}

Keywords: Gannan tea-picking opera, female role, dance performance, morphological characteristics

\section{Basic overview of Gannan tea-picking opera}

Gannan tea-picking opera is one of the native Operas of the Han Nationality in Gannan. Gannan tea-picking opera originated in the late Ming and early Qing Dynasties in Jiulong Mountain, Anyuan County. It is a local opera gradually developed from the folk "Chalandeng", "Caicha Gewu and "Sanjiaoban" with a history of more than 400 years. Gannan began to pay tribute to tea in the Song Dynasty, when tea gardens were flourishing and tea enjoyed a reputation. The Chashangewu probably came into being with the development of tea trade at this time, and was widely spread in the Ming Dynasty. In the late Ming and early Qing dynasties, "Sanjiaoxi" began to emerge, and professional squad appeared. In the early stage of tea picking with dances, two sisters went up to the mountain to pick tea, singing the song of "Tea in December", and sometimes singing the song of "tea in four seasons". In order to attract the focus of audience, artists generally sang the song of the "Tea in December"from December back to the first month. The sisters held tea baskets singing and dancing, and tea- picking children held paper fans, walking in short steps, which was called "Chadeng ", also called "Sisters picking tea leaves". This is the formation of the original Gannan tea opera original program, which is also the prototype of the Sanjiaoban.

The comprehensive artistic style of Gannan tea-picking opera is not as rigorous and standardized as the expression form of classical opera, which is closer to life, and most of the artists are from the countryside. After entering the city from the countryside, Gannan tea-picking opera has gone through more than 60 years of hardships. The content of the performance is constantly enriched, the forms and means of service are constantly updated, the management system is gradually established and improved, the artistic skills are continued and passed on, the ideological organization construction is further carried out, and the overall quality of the performance level is constantly improved through the practice of "transformation in people, opera and institutions".

Since the Ming Dynasty, stimulated by the national economic activity and increasing population, tea production in Jiangnan gradually became prosperous, and a corresponding "tea culture" fever appeared among the people, which was actively responded to by people from all social strata. For example, Tang Xianzu (1550-1616), a great playwright of the Ming Dynasty and a native of Jiangxi province, wrote in his poems that "the spring breeze in the woods sang the song of tea picking". In his immortal work The Peony Pavilion, it is written that when Du Bao, the governor of Nan 'an, came to the outskirts of the city to "persuade farmers", there appeared a pair of women holding tea baskets singing at the side of the field. The song went as: "With the grain rain, fresh tea leaves were picked". During the Reign of Wanli in the Ming Dynasty (15731620), the biography of Mr. Xiong Xiupu in the genealogical tree of The Xiong family in Yaling, Shicheng County, which was reconstructed, also recorded that the creek was sung the song of planting rice seedlings and picking tea", indicating that 
Gannan tea-picking opera was quite popular at that time.

By the end of the Ming Dynasty, several songs and dances with simple characters and props such as fans and tea baskets appeared in Hakka area one after another. After the formation of large-scale tea production, tea merchants from different regions frequently exchanged with each other, and the festival ceremony of "Kaichashi" and "Shouchashi" appeared. Tea farmers and tea merchants have made more programs about tea. For example, in the Chadengdiao of Ruijin, there are songs of picking tea, watching tea, calculating money for purchasing tea and delivering tea. In the song, there are characters such as "tea guest" and "tea sister". These programs are also used to send New Year greetings to tea houses and shops during chung Hom Festival. In order to create a lively atmosphere, some people carry various kinds of lanterns while traveling, while others perform with horse lanterns and hua-gu. With the accompaniment of suona, gong and drum, they sing the tune of the horse lantern while running. After the circle is formed, some simple plays will be performed.

On the basis of the Chalandeng, the pattern of Liangdan and Yichou was further established to gradually form the "Sanjiaoban" based tea picking opera. Gradually, it broke away from the limitation of only reflecting tea as the main content of Dengcai, and staged a number of plays reflecting love, production and life with a broader vision, such as Sijiefanqing, Daquanfu, Maizahuo and Dashaobiaoge, etc. These plays are performed by Liangdan and Yichou accompanied by the positive and negative strings and gongs and drums of the main instrument of the tea picking play. Since then, tea picking opera has entered the "Sanjiaoban" period. But in the process of the development "Sanjiaoban", there appeared a very meaningful attempt, that is "Tea picking in Jiulongshan".

After the 1950s, Tea-leaf Picking Opera entered a new heyday. More than ten professional tea picking troups have been set up in southern Jiangxi, and hundreds of artists have been properly settled. The people's government has also trained a number of well-educated and specialized young actors, provided full-time directors and musicians, and set up special funds, theaters and rehearsal venues. Since then, Tea-leaf Picking Opera has embarked on the road of urbanization, standardization, standardization and specialization. The quality and performance of actors have been greatly improved. After being processed and adapted, the opera such as Bupixie, Diaoxi, Shaomeizi, Laoshaopei were performed in Beijing and praised by the central leadership and the circle of capital literature and art. Gannan tea-picking opera troupe also gradually develop to have hundreds of staffs, equipped with a mix of Chinese and western bands and lighting, audio equipment, and Chatongge, Denghuo qiyuan, Lianmeizi, Huadengxiaonzi, Shangeqing, Zenmetanbulong and Shiqi were performed in Beijing with the "Wenhua Award" and "Five One Project" and other awards.

\section{2. "Xiao Dan" and "Cai Dan" in Gannan tea-leaf picking opera}

In the middle of the Ming Dynasty, the tea-picking lamps of Jiangxi and Guangdong provinces exchanged with each other, and the tea-picking lamps in south Jiangxi witnessed a new development. On the basis of two male tea picking teams and twelve female tea picking teams, the pattern of two women and one man is made (the female is the eldest sister, the second sister, and the male is called the tea boy), and the original "Tea picking Song in December" is changed into antiphonal singing by sisters, with tea boys interweaving among them. The name of "Sisters Picking Tea" is a song and dance opera with simple plot and characters, which shows the sisters held a tea basket up the mountain to pick tea, singing and dancing, the tea boy held a hand paper fan, gag. Since then, So far, the Sanjiaoxi of Liangdan and Yichou came into being. The dance image of female roles in Gannan tea-picking opera is basically women of all ages attitude performance of different forms of the charm, from teenage and women of different ages.

\subsection{Xiao Dan}

"Xiao Dan", also known as "Hua Dan", refers to the young married women who were kind, simple, intelligent, gentle and beautiful, hard-working and they were described as lovely, charming delicate and sweet in performance. As the role played is for the energetic youth and they were less constrained by life with inadequate experience in life, so they were demonstrated as innocent, simple, open youth with justice, and therefore, they have the courage to express their feelings. For example, the girl (Xiao Dan) in the Gannan Tea picking song and dance opera "Whistle Sister" performs the graceful and graceful dance of young women by stepping on the stage, waving her hands and flowers in her hands.

\subsection{Cai Dan}

Cai Dan is a character to have display a class of idle citizens, who were middle-aged or elderly women in their 40s or 50s (such as shopkeepers, matchmakers, etc. ). The character of the figures are mostly coquettish and violent with the performance devices of exaggeration, and the dance movement range is larger, thus adequate in cartoon characteristics. In the performance, handkerchief, pipe and other small props were added in order to facilitate the deepening of the character performance. In addition, there are Laodan, Laosheng and other roles. For example, the shop sister-in-law in the Gannan tea 
picking song and dance opera "Chatongdadian" shows the character characteristics of "Cai Dan" to you most vividly.

\section{Morphological characteristics of "female roles" in Gannan tea-picking opera}

\subsection{Dance performance form of "female roles" in Gannan tea-picking opera}

The "dance" in Gannan tea-picking opera is a one-act rural dance. It is an artistic achievement accumulated from life refined and processed by numerous predecessors based on people's love and pleasure and through long-term hard work. It clearly reflects different thoughts, beliefs, pursuits and aesthetics. Early Gannan tea-picking opera, in the process of performing with a variety of folk lanterns and dances, mutual learning, and from the absorption of rich nourishment, this on the development and innovation of Gannan tea-picking opera, has produced inestimable role. Between Ming dynasty and early qing to the formation of the "three feet class" has hedong, hexi two genres, hexi much affected by the martial arts dance form, hedong dance forms to stretch, stable in high, medium and pile, a beautiful dance, graceful "Liangdanyiqchou" Gannan tea-picking opera is the most representative mode of performance, including "stage" is divided into "XiaoDan" and "usually of the vicious type". The dance performance mode and movement form of "Three inch Golden lotus type Xiao Dan" and "exaggerated cartoon type Colorful Dan" also represent the characteristics of female dance performance style of Gannan tea-picking opera.

\subsection{Dynamic characteristics of dance performance of "female roles" in Gannan}

\subsubsection{Yao}

"Yao" is constrained by the bondage of the feudal ethics (foot binding). In this case, labor production should be engaged, so the old artist created the Gannan tea-picking opera unique dance steps "small steps", namely "step on the stage", "twist step") to highlight the "female shake" dance posture and manner, just like carp wagging its tail, delicate and beautiful. Because of the fertile soil in Gannan, Jiangxi people since the ancient times with the farm work is the foundation of the economy. The course of traditional folk dance of the woman's "female shake" dynamic law of morphological analysis found that the dynamic law is driven by his legs around the center of gravity transformation of gluteal muscle (hip) between the pelvis and the body. It reflects the relationship with farmland work, showing the movement of people when picking tea, highlighting the "Yao" manner of female characters, such as the spring wind exhausted willow, such as sandalwood smoke, steady and gentle; such as the carp wagging its tail, delicate and beautiful.

\subsubsection{Chan}

Gannan tea-picking opera is very particular about rhythm and rhythm, "tremble" in the female roles is the Gannan teapicking opera female roles basic rhythm. In the dance of Gannan tea-picking opera, the sinian Angle needs to hold a variety of props to show the plot of going up the hill, going down the hill, picking tea, crossing the bridge, entering the door and so on, all of which show similar movements with the short man step. But in the performance of the "dwarf step", the corner needs to have a more flexible, nifty one - face, and the quiver movement, can let the woman's pace is just with soft, to show the feminine feminine one - face. With the short step, it can show "men walk and women shake", "men tease women qiao" scene. The movement of "flutter" should be carried out in coordination with the singing, and the center of gravity should move along with the rhythm. It should sink during downbeat and rise during light beat, showing the effect of tremor. In the "flutter" at the same time, the two shoulders should also follow the rhythm of the rhythm, left and right swing, feel like in the figure of eight - the same. Only the fibrillation of the movement practice, to make the overall movement coherent not abrupt. "Fibrillation" is a "important link in the action of Gannan tea-picking opera connection, because each" fibrillation "between the action and posture will have a pause, so that even if the sudden change of rhythm and posture, will become natural and smooth, no trace. At this time, if you can in the waist, hands and other positions, with some improvised small movements, will make the tea picking opera more interesting to watch. With the development of Gannan tea-picking opera, many impromptu and modern elements are also integrated into the performance characteristics of The Sinian Corner. For example, ganzhou large tea picking opera "Eight Sons join the Army" is integrated with the elements of modern dance. On the basis of the essence of traditional Hakka, it shows the spiritual appearance and life characteristics of the new Hakka people.

\subsubsection{Niu}

In the dance of "female roles" in Gannan tea-picking opera, the performer's waist needs to be very flexible and can be used freely, so as to show the shape characteristics of "twist". The "twist" of The Gannan tea-picking opera is like jumping a rubber band, which needs to be recovered immediately after the twist, and the axis must always be kept between the lower abdomen and the waist, so as not to shake. If the "twisted" action is not good, plus tea-picking opera props and pace is numerous, the performer of action will be very not harmonious, this action can performance stage, do a naughty vivid 
image, such as in the women's solo "woman" in the "family" performers by the action of "twisted", showed the matchmaker of lifelike image.

\subsubsection{Rao}

In the Gannan tea-picking opera, "Rao" is also an important basic skill of the Gannan tea-picking opera. In the Gannan tea-picking opera, because there are various props in the hands of the Sinian Angle, so in the round, the Sinian Angle can be through the fan, handkerchief and so on to show a more rich meaning. "Fan flower" is ugly, denier all prepare one of the basic action. Artists say, "Picking tea without a fan is like eating without chopsticks." It can be seen that fans play an important role in the song and dance of picking tea. There are "single fan flower" and "double fan flower "(double fan flower is limited to dance). The art is: "five fingers flower head in the sky, four fingers flower head in front, three fingers flower hit four sides, two fingers flower shake chest, yun, press, grasp, shake on the stomach. In Gannan tea-picking opera, the circle is also an essential link when the sinian Angle comes into play. It can be the switch of different scenes to become natural and smooth, reflecting the beauty of implicative and the aesthetic feeling of combining hardness and softness.

\section{Conclusion}

As a dynamic art of human body and a regional cultural phenomenon, Gannan tea-picking opera began to be carried out by a large number of professional dancers in the fields of Gannan since the 1950s and 1960s, so that Gannan tea-picking opera was separated from the "opera". In Gannan tea-picking opera, dance dynamic characteristics of the clown are very rich, and have a unique style. The style of dance woman's dynamic is not strong, and the dynamic characteristics and the dance is not rich, so the author hopes to look for the woman's dance dynamic route characteristics through the rich variety of fan take skills in order to rich stage dance dynamic performance characteristics, and draw lessons from harlequin dance rhythm characteristics to rich the features of dance rhythm of "female roles". The external dynamic and potential cultural connotation of the Gannan tea-picking opera is the typical sign that clearly distinguish it from other folk dances. They are also the key for people to fully understanding and deeply grasping its essence, and the basis for promoting its inheritance and development, which is worth our attention and research.

\section{$\underline{\text { References }}$}

[1] Ganzhou District Annals Compilation Committee. A Study on the influence of water quality on water quality [M]. People's Publishing House; 1989.

[2] Du Suhua. Discussion on the Morphological Characteristics of Dance performance of female roles in Gannan Tea-picking Opera[J]. Brand. 2015, (6): 106.

[3] Duan Dibo. On the Dynamic Performance of the Female Roles Dance in the Tea-picking Opera [D]. Beijing Dance Academy. 2016.

[4] A Study on the Morphological Characteristics and Cultural Implications of Ma Qiang's Gannan Tea-picking Dance. Fujian Tea. 2018; 08.

[5] Morphological Characteristics and Cultural Connotation of Dong Liusha's Gannan tea-picking opera. Fujian Tea. 2018; 11.

[6] Liu Bin, Style Characteristics of Gannan Tea-picking Dance[J]. Art Review. 2006; 11. 